\title{
Preventable deaths among youth in South Africa: Measuring life expectancy in the absence of non-communicable diseases and its implications for the healthcare system
}

\author{
N de Wet-Billings, PhD (Demography and Population Studies) \\ Demography and Population Studies, Schools of Social Sciences and Public Health, Faculties of Humanities and Health Sciences, \\ University of the Witwatersrand, Johannesburg, South Africa
}

Corresponding author: $N$ de Wet-Billings (nicole.dewet-billings@wits.ac.za)

\begin{abstract}
Background. Non-communicable diseases (NCDs) cause premature mortality among youth. Associated with lifestyle and behavioural choices, these diseases and deaths can and should be prevented among young people. This article presents data showing the gains in life expectancy among youth in the absence of NCD causes of death.

Objectives. To estimate the levels of NCD mortality among youth (15 - 24 years of age) in South Africa (SA) and show the current and projected additional years of life gained with the elimination of heart disease, cancer and diabetes.

Methods. This was a cross-sectional study using 20 years of death notification forms from SA (1997 - 2016). The data were nationally representative and the sample was 62395 youth deaths (age 15 - 24 years) from the selected NCDs. Cause-specific mortality rates, expressed as percentages, were estimated by age group and sex. Cause-deleted life-table techniques were used to estimate current and projected life expectancy $\left(e_{\mathrm{x}}\right)$ and life expectancy in the absence of specific NCDs $\left(\mathrm{e}_{\mathrm{x}}^{-\mathrm{i}}\right)$.

Results. Death rates from NCDs are increasing over time among youth. Total death rates from cancer increased from $1.09 \%$ in 1997 2001 to $1.51 \%$ in 2012 - 2016. Female death rates from heart disease are almost double those for males. The number of additional years of life gained with elimination of these causes ranges from 2.2 to 10.3. Projected life expectancies show that males could gain as much as 1 additional year and females 1.06 years by 2035 .

Conclusions. Urgent action needs to be taken to prevent further mortality from non-communicable causes among youth. The results of this study are important to the SA healthcare system and to public health practitioners whose aim is to reduce the strain on public resources and reduce mortality among youth. Future studies should estimate the extent of NCD mortality in households and communities with the aim of developing macro-level interventions.
\end{abstract}

S Afr Med J 2021;111(4):361-364. https://doi.org/10.7196/SAMJ.2021.v111i4.14790

In sub-Saharan Africa, mortality rates from non-communicable diseases (NCDs) are projected to increase from $\sim 40 \%$ in the early 2000 s to almost $79 \%$ of all deaths by $2030 .^{[1]}$ The leading non-communicable causes of death in the region, among all age groups, are stroke, ranging from $0.03 \%$ to $0.7 \%$, diabetes $(0-16 \%)$, hypertension $(6-48 \%)$ and obesity $(0.4-43 \%) \cdot{ }^{[2]}$ In South Africa (SA), NCDs account for $39 \%$ of all deaths; specifically, heart disease contributes $\sim 100$ deaths per 100000 males and 60 deaths per 100000 females. ${ }^{[3]}$ While genetic components contribute to the development of these diseases, lifestyle and behavioural factors, including physical inactivity, inadequate diets and stress, are also known causes of NCDs. ${ }^{[4]}$

Youth (15 - 24 years of age) are becoming increasingly susceptible to NCDs owing to exposure to cheap fast foods and sedentary lifestyles, which places them at increased risk of lifestyle diseases such as obesity and diabetes. ${ }^{[5,6]}$ The challenges youth in low- and middle-income countries face, namely poverty, unemployment and lack of access to quality education, increase their risk of high blood pressure and coronary heart disease associated with stress. ${ }^{[7]}$ In SA, there is evidence that youth suffer from overweight and obesity, hypertension and diabetes. ${ }^{[8]}$ As many as $22.9 \%$ of 7 - 18-year-olds across 14 schools in the country were found to be overweight or obese, ${ }^{[9]}$ and in another study, $29.7 \%$ of learners in KwaZulu-Natal Province had prehypertension. ${ }^{[10]}$ Furthermore, while infectious diseases, especially HIV/AIDS, and injury have been extensively studied as causes of death among youth in $\mathrm{SA},{ }^{[1,12]}$ there is a dearth of research on NCD mortality among youth in the country.

Youth in SA, and all other countries, are future parents, employers and employees, making them pivotal drivers of social and economic change and growth. For these reasons, it is of the utmost importance that young people survive and become healthy adults. It is therefore a priority of many governments, including SA's, to ensure that youth mortality and morbidity are curbed. ${ }^{[13]}$ NCDs not only compromise the survival of youth to adulthood, but are also chronic diseases that affect, among other things, their labour force participation and their ability to be financially independent adults. ${ }^{[14]}$ Efforts therefore need to be made to understand the extent of NCD mortality among youth and to identify the impact these diseases have on the longevity of young people, with the purpose of highlighting the importance of preventing NCDs.

\section{Objectives}

To estimate life expectancy among youth (15 - 24 years of age) in SA in the absence of certain NCD causes of death.

\section{Methods}

Data for this study came from SA death notification forms (DNFs), made publicly available from Statistics South Africa (http://www. 
statssa.gov.za). The data span 20 years of DNFs from 1997 to 2016. Population estimates were derived from the General Household Surveys for the same period. Specific causes of NCD death were identified through the main cause of death (cause A) and the International Classification of Diseases, 10th revision (ICD-10) codes for heart disease, cancer and diabetes. ${ }^{[15]}$ Youth from all racial groups and provinces were represented in the study.

The study population was young (15-24 years of age) male and female deaths from the selected NCDs. Youth were identified through the age at death variable, and for the 20-year period, 556607 communicable disease (88.79\%) and NCD (11.21\%) deaths were recorded among youth. The diseases selected for this study contributed the most NCD deaths for the period. These were heart disease with 55870 deaths among 15 -24-year-olds, cancer with 6397 deaths, and diabetes with 128 deaths. Among the deaths due to heart disease, some of the specific entities were ischaemic heart disease $(2.86 \%)$, cerebrovascular disease $(16.30 \%)$, peripheral artery disease (1.02\%), pulmonary heart disease (5.90\%) and other forms of heart disease (69.20\%). Among deaths from cancer, $64.89 \%$ did not have a specific type, $16.27 \%$ were from lymphoid, haematopoietic and related tissue cancer, $7.61 \%$ were from mesothelial and soft-tissue cancer, and $3.92 \%$ were from cancer of the digestive system.

To analyse the data, cause-specific death rates for each NCD cause by sex of the youth population were calculated. This was a summation of the cause-specific deaths divided by total deaths (all causes) for the same age group in 5-year intervals multiplied by $100 .{ }^{[16]}$ To derive life expectancy and cause-deleted life expectancy, standard abridged life tables were used in 10-year age intervals to capture 15 - 24-yearolds. ${ }^{[17]}$ Initially, 5-year age intervals were used, but the differences in life expectancy and cause-deleted life expectancy between 15 19-year-olds and 20 - 24-year-olds were marginal, so 10-year abridged methods were selected. Projections of life expectancy to 2030 and 2035 were done using the United Nations method. ${ }^{[18]}$

\section{Results}

Table 1 shows the percentage distribution of select NCD deaths by sex and period. It can be seen that heart disease contributed $7.26 \%$ of all deaths of young (15 - 24-year-old) males in 1997 - 2001 and that this figure decreased to $6.90 \%$ in 2002 - 2006, before increasing to $7.07 \%$ in 2012 - 2016. Cancer contributed $0.98 \%$ of all deaths of young males in 1997 - 2001 and then increased throughout the periods to $1.30 \%$ in 2012 - 2016. Diabetes had the lowest contribution to deaths at $0.012 \%$ in 1997 - 2001, but also increased steadily to $0.070 \%$ in 2012 - 2016. Among young females 15 - 24 years of age, $15.00 \%$ of all deaths in 1997 - 2001 were due to heart disease; this decreased to $11.62 \%$ in 2002 - 2006, but then increased to $14.65 \%$ in $2012-2016$. Cancer caused $1.21 \%$ of all deaths of young females in $1997-2001$, also decreasing in 2002 - 2006 to $0.96 \%$ before increasing to $1.78 \%$ in 2012 - 2016. Diabetes contributed $0.042 \%$ of all deaths among young females in 1997 - 2001, declined to $0.036 \%$ in 2002 - 2006, and increased to $0.209 \%$ in 2012 - 2016.

Table 2 shows the cause-deleted life expectancy $\left(\mathrm{e}_{\mathrm{x}}^{-\mathrm{i}}\right)$ and number of years gained without the disease by sex and age group for the period 1997 - 2016. Males have the most to gain in the absence of heart disease, at 7.9 years for 15 - 19-year-olds and 10.3 years for 20 - 24-year-olds. Also, between 2.2 and 2.7 years could be gained in the absence of cancer and between 0.6 and 4.7 years in the absence of diabetes. Among females, 5.1 years could be gained for 15 - 19-yearolds in the absence of heart disease, and 4.9 years for 20 - 24-yearolds. If cancer were eliminated, young females could gain between 2.2 and 3.3 years, and if diabetes were eliminated, between 2.2 and 5.4 years.

Fig. 1 shows the life expectancy (all causes) and cause-deleted life expectancies for heart disease, cancer and diabetes for males aged 15 - 24 years, projected to 2035 . The projected cause-deleted life expectancies show that young males have the most years to gain without heart disease (no heart disease) as cause of death. By 2030, without heart disease deaths in the population, life expectancy (all causes) could increase from 41.2 years to 42.6 years and by 2035 , from 41.7 years to 42.7 years. The gains in life expectancy without cancer could be 0.7 years by 2030 (from 41.2 to 41.9 years) and 0.5 years by 2035 (from 41.7 to 42.2 years). Without diabetes, young males could gain 0.2 years by 2035 .

Similar to males in the same age group (15 - 24 years), females have most to gain by the elimination of heart disease (Fig. 2). With the elimination of heart disease, by 2030, female life expectancy

Table 1. Cause-specific death rates (\%) by sex and select non-communicable diseases and period of death among youth (15 - 24 years of age) in South Africa

\begin{tabular}{|c|c|c|c|c|c|c|c|c|c|}
\hline \multirow[b]{2}{*}{ Year of death } & \multicolumn{3}{|c|}{ Male } & \multicolumn{3}{|c|}{ Female } & \multicolumn{3}{|c|}{ Total } \\
\hline & Heart disease & Cancer & Diabetes & Heart disease & Cancer & Diabetes & Heart disease & Cancer & Diabetes \\
\hline $1997-2001$ & 7.26 & 0.98 & 0.012 & 15.00 & 1.21 & 0.042 & 10.91 & 1.09 & 0.03 \\
\hline $2002-2006$ & 6.90 & 1.02 & 0.020 & 11.62 & 0.96 & 0.036 & 9.52 & 0.99 & 0.03 \\
\hline $2007-2011$ & 6.86 & 1.11 & 0.018 & 12.54 & 1.13 & 0.023 & 9.69 & 1.12 & 0.02 \\
\hline $2012-2016$ & 7.07 & 1.30 & 0.070 & 14.65 & 1.78 & 0.209 & 10.34 & 1.51 & 0.13 \\
\hline
\end{tabular}

Table 2. Life expectancy, cause-deleted life expectancy and number of years gained without select non-communicable diseases for the period $1997-2016$ in South Africa

\begin{tabular}{|c|c|c|c|c|c|c|c|c|}
\hline \multirow[b]{2}{*}{ Sex } & \multirow[b]{2}{*}{ Age group (years) } & \multirow[b]{2}{*}{$\mathbf{e}_{\mathrm{x}}$} & \multicolumn{2}{|c|}{ Heart disease } & \multicolumn{2}{|c|}{ Cancer } & \multicolumn{2}{|r|}{ Diabetes } \\
\hline & & & $\mathrm{e}_{x}^{-i}$ & Years gained & $\mathrm{e}_{x}^{-i}$ & Years gained & $\mathrm{e}_{x}^{-\mathrm{i}}$ & Years gained \\
\hline \multirow[t]{2}{*}{ Male } & $15-19$ & 44.5 & 52.4 & 7.9 & 46.7 & 2.2 & 45.1 & 0.6 \\
\hline & $20-24$ & 39.5 & 49.8 & 10.3 & 42.2 & 2.7 & 44.2 & 4.7 \\
\hline \multirow[t]{2}{*}{ Female } & $15-19$ & 45.4 & 50.5 & 5.1 & 48.6 & 3.2 & 47.6 & 2.2 \\
\hline & $20-24$ & 40.9 & 45.8 & 4.9 & 43.1 & 2.2 & 46.3 & 5.4 \\
\hline
\end{tabular}




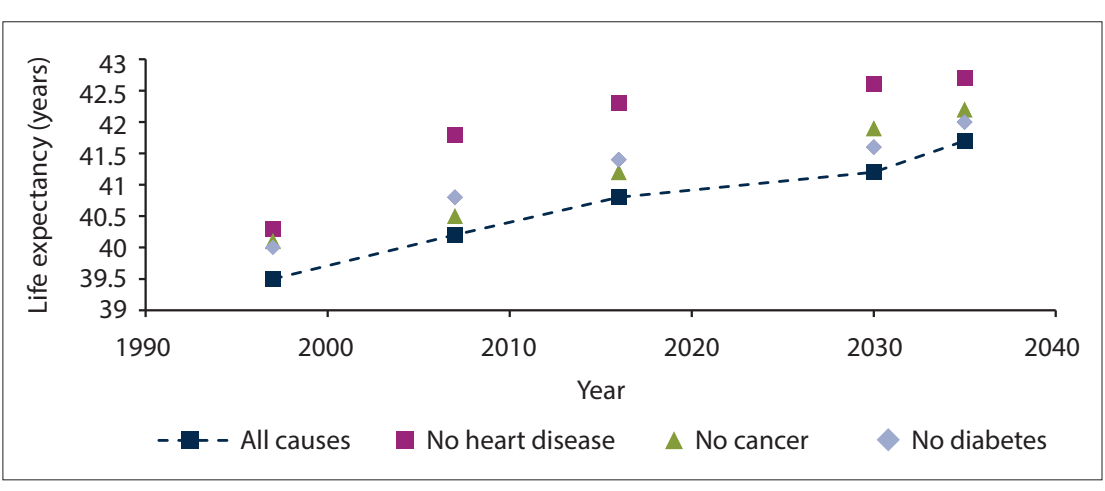

Fig. 1. Life expectancy and cause-deleted life expectancy for males aged 15 - 24 years, 1997 - 2035.

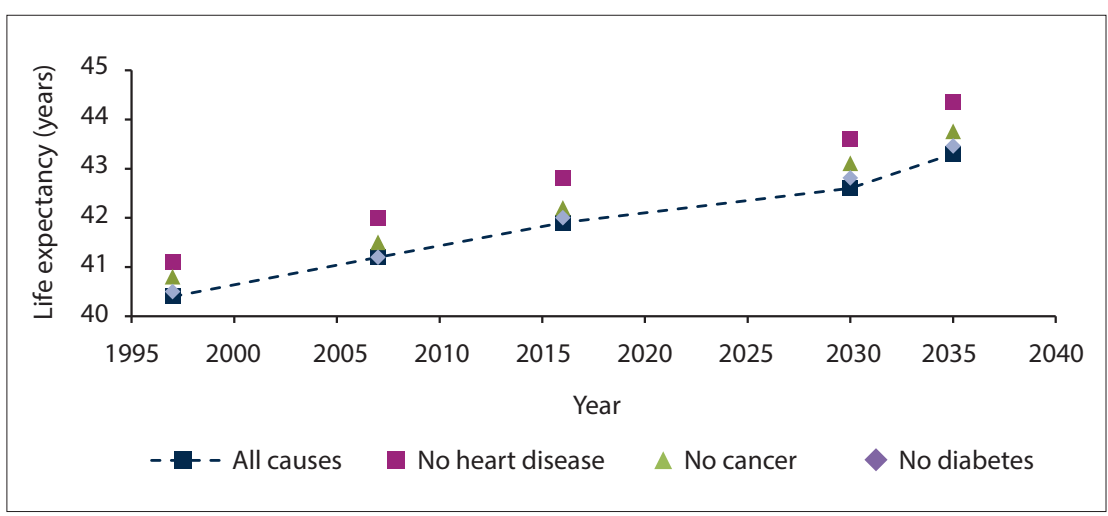

Fig. 2. Life expectancy and cause-deleted life expectancy for females aged 15 - 24 years, 1997 - 2035.

could increase from 42.6 years (all causes) to 43.61 years (gain of 1 year), and by 2035 females could gain 1.06 years, from 43.3 years (all causes) to 44.36 years. Lesser gains can be seen for cancer at 0.51 years (43.11 years) in 2030 and 0.46 years ( 43.76 years) in 2035 . With the elimination of diabetes, young females could expect to gain $0.21(42.81$ years) and 0.16 ( 43.46 years) additional years by 2030 and 2035 , respectively.

\section{Discussion}

The purpose of this study was to identify the extent of NCD deaths and to estimate the additional years of life gained without these non-communicable causes among youth in SA. This study is needed because SA already has a resource-constrained healthcare system, ${ }^{[19]}$ and with the planned implementation of National Health Insurance, ${ }^{[20]}$ there is a need to identify causes of premature death and disease that can be prevented.

The main finding of this study is the considerable additional years of life youth can expect to live without heart disease, cancer and diabetes as the main causes of death. Since mortality is based on the premise of competing risks, it is not unexpected that gains in life expectancy will be the result of the elimination of specific causes of death. ${ }^{[21]}$ However, the more years gained is an indication of the extent of the problem in the population. In this study, between 2.2 and 10.3 additional years of life could be gained, which is evidence of the high burden of NCDs in the country. In comparison with estimates for HIV/ AIDS, where the gains in life expectancy are between 2 and 6 additional years for 15 - 34-year-olds, ${ }^{[1]}$ the results of this study show that NCD mortality is as burdensome as infectious disease mortality. These results on life expectancy mean that youth could live much longer, healthier lives.

NCD deaths among youth are also increasing over time in SA. To place this result in the context of the disease burden in the country, NCDs in general are increasing in the population, with the prevalence of diseases such as diabetes increasing from $5 \%$ to nearly $10 \%$ among females during the period $1980-2014 .^{[22]}$ Other NCDs with a high burden in the SA population include cardiovascular disease and cancer, which respectively contribute $19 \%$ and $10 \%$ of all deaths. ${ }^{[23]}$ Also, with high rates of poverty and poor access to healthcare in the country, these disease distributions turn into mortality rates due to lack of management and treatment. Of particular concern is the impact increasing NCD rates will have on the economy, with one study estimating that salt regulation will assist in reducing hospitalisation costs by ZAR300 million (USD16.7 million) per year through the prevention of strokes. ${ }^{[24]}$ In addition to spending on healthcare on an individual level, NCDs are associated with fewer working hours and less productivity, which in turn leads to lower salaries and higher unemployment. ${ }^{[14,25]}$ Youth, therefore, who are the future labour force participants, not only face compromised employment opportunities but are also at risk of not completing school. One study in the USA found that $11.18 \%$ of young people with diabetes, $21.07 \%$ with high blood pressure/ hypertension and $6.17 \%$ with heart disease will drop out of secondary education, ${ }^{[26]}$ while a study from SA showed that adolescents with at least one NCD are 1.61 times more likely to repeat a grade at school than those with no disease. ${ }^{[27]}$

Females have higher mortality rates from NCDs than males. It has also been found that young females have higher mortality rates from communicable diseases, including tuberculosis $(16.8 \%$ v. $11.8 \%$ in young males), AIDS (13.0\% v. 7.7\%) and influenza and pneumonia $(6.1 \%$ v. $3.4 \%))^{[28]}$ Young females in SA face high levels of genderbased violence, poverty and inequality, all of which compromise their health and healthseeking behaviour ${ }^{[2,30]}$ and explain their disproportionate disease and mortality rates.

The results of this study are important, because NCDs are preventable and treatable through adjustments to lifestyle and behaviour, as well as early detection. ${ }^{[14]}$ Behaviours such as physical activity, eating a healthy diet, stopping smoking and reducing alcohol consumption can also prevent the development of NCDs in young people. ${ }^{[5,31]}$ The results, therefore, are closely linked to the prevention and treatment of obesity and hypertension to reduce the risks of heart disease and diabetes, and early detection through medical testing to reduce deaths due to cancer.

\section{Study limitations}

The study is subject to some limitations. First, DNFs, being part of the vital registration data, are known to be subject to under-reporting, particularly in the earlier periods. ${ }^{[32]}$ Second, the DNFs are subject to incompleteness, and misclassified and unspecified causes of death. These were all dropped from the study. Third, this study used broad categories of NCDs to determine life expectancy, and this is not suitable for targeted interventions against specific types of heart disease and cancers. However, the study does prove the overall relevance of 
preventing these NCDs by presenting the gains if all types of these diseases are eliminated from the mortality experience of young people.

\section{Conclusions}

There is a need for urgent intervention to prevent the rising rates of NCD mortality among youth. SA can prevent premature mortality due to NCDs among youth, and gain additional years of life, through stronger implementation of prevention and treatment services for lifestyle diseases. For public health and the healthcare system in the country, these results show that more effort is needed to reduce incidences of NCD among youth, and that treatment and management of these diseases are needed to prevent mortality. The available evidence shows that youth can survive and gain in the absence of these NCDs, and with this information in mind, programmes and policies should encourage healthier lifestyles and earlier detection of NCDs among youth through supporting physical exercise and nutrition at schools, as well as by making detection of these conditions more affordable and available at clinics and hospitals throughout the country. Future research on this topic should examine the extent of NCD mortality in the households and communities where youth reside. This research could highlight broader, contextual areas that could be targeted for nationwide intervention. Finally, a study seeking to understand why youth do not access appropriate treatment and management services is needed to better understand NCD health status, and how morbidity becomes mortality.

Declaration. None.

Acknowledgements. None.

Author contributions. Sole author.

Funding. This work is based on research supported wholly by the SA National Research Foundation (grant no. 116326).

Conflicts of interest. None.

1. World Health Organization. Global status report on noncommunicable diseases 2014. WHO, 2014. https://www.who.int/nmh/publications/ncd-status-report-2014/en/ (accessed 3 March 2020). 2. Dalal S, Beunza JJ, Volmink J, et al. Non-communicable diseases in sub-Saharan Africa: What we know now. Int J Epidemiol 2011;40(4):885-901. https://doi.org/10.1093/ije/dyr050

3. Nojilana B, Bradshaw D, Pillay-van Wyk V, et al. Persistent burden from non-communicable diseases in South Africa needs strong action. S Afr Med J 2016;106(5):436-437. https://doi.org/10.7196 SAMJ.2016.v106i5.10776

4. Boutayeb A, Boutayeb S. The burden of non communicable diseases in developing countries. Int Equity Health 2005;4(1):2. https://doi.org/10.1186/1475-9276-4-2

5. Onagbiye SO, Tshwaro RMT, Barry A, Marie Y. Physical activity and non-communicable disease risk factors: Knowledge and perceptions of youth in a low resourced community in the Western Cape.

6. Uddin R, Lee E-Y, Khan SR, Tremblay MS, Khan A. Clustering of lifestyle risk factors for noncommunicable diseases in 304,779 adolescents from 89 countries: A global perspective. Prev Med
condin R, Lee E-Y, Kha SR, Tremblay MS, Khan A. Clustering of lifestyle risk factors for noncommunicable diseases in 304,779 adolescents from 89 count
2020;131:105955. https://doi.org/10.1016/.ypmed.2019.105955
7. Ibrahim MM, Damasceno A. Hypertension in developing countries. Lancet 2012;380(9841):611619. https://doi.org/10.1016/S0140-6736(12)60861-7

8. Bradshaw D, Steyn K, Levitt N, Nojilana B. Non-communicable diseases - a race against time. South African Medical Research Council. http://www.health.uct.ac.za/usr/health/research/groupings/ cdia/downloads/MRC_policy_brief.pdf (accessed 5 March 2021).

9. Negash S, Agyemang C, Matsha TE, Peer N, Erasmus RT, Kengne AP. Differential prevalence and associations of overweight and obesity by gender and population group among school learners in South Africa: A cross-sectional study. BMC Obes 2017;4:29. https://doi.org/10.1186/s40608-017-0165-1

10. Bhimma R, Naicker E, Gounden V, Nandlal L, Connolly C, Hariparshad S. Prevalence of primary hypertension and risk factors in grade XII learners in KwaZulu-Natal, South Africa. Int J Hypertens 2018;2018: article ID 3848591. https://doi.org/10.1155/2018/3848591

11. De Wet N, Oluwaseyi S, Odimegwu C. Youth mortality due to HIV/AIDS in South Africa, 2001 2009: An analysis of the levels of mortality using life table techniques. Afr J AIDS Res 2014;13(1):1320. https://doi.org/10.2989/16085906.2014.886605

12. Leeper S, Myers J, Patel M, Reddy P, Martin IB, van Hoving DJ. Assault-injured youth in the emergency centres of Khayelitsha, South Africa: Baseline characteristics \& opportunities for intervention. Injury 2019;50(12):2220-2227. https://doi.org/10.1016/j.injury.2019.10.014

13. National Department of Health, South Africa. National Adolescent and Youth Health Policy 2017. Pretoria: Mzantsi Wakho, 2017. https://www.saferspaces.org.za/resources/entry/nationaladolescent-youth-health-policy-2017 (accessed 3 March 2020).

14. Lawana N, Booysen F, Tsegaye A, Kapingura FM, Hongoro C. Lifestyle risk factors, noncommunicable diseases and labour force participation in South Africa. Dev South Afr 2020:37(3):446-461. https://doi.org/10.1080/0376835X.2019.1678459

15. World Health Organization. International Classification of Diseases and Related Health Problems. Geneva: WHO, 2016. https://www.who.int/standards/classifications/classification-of-diseases (accessed 10 April 2020)

16. Chiang CL, World Health Organization. Life Table and Mortality Analysis. WHO, 1979. https:// apps.who.int/iris/handle/10665/62916 (accessed 10 April 2020).

17. Smith DP. Formulae for cause-deleted life tables. Stat Med 1985;4(2):155-162. https://doi. org $/ 10.1002 / \operatorname{sim} .4780040206$

18. Mathers CD, Loncar D. Updated projections of global mortality and burden of disease, $2002-2030$ : Data sources, methods and results. Geneva: World Health Organization, 2005. https://www.who.int/ healthinfo/statistics/bod_projections2030_paper.pdf (accessed 5 March 2020).

19. Morudu P, Kollamparambil U. Health shocks, medical insurance and household vulnerability: Evidence from South Africa. PLoS ONE 2020;15(2):e0228034. https://doi.org/10.1371/journal. pone. 0228034

20. Jones S. NHI: What's all the fuss about? Personal Finance 2019;464:2. https://www.bellanmedia.co.za/ wp-content/uploads/2020/07/Personal-Finance-September-2019-1.pdf (accessed 23 February 2021)

21. Ho JY. The contribution of drug overdose to educational gradients in life expectancy in the United States, 1992 - 2011. Demography 2017;54(3):1175-1202. https://doi.org/10.1007/s13524-017-0565-3

22. World Health Organization. WHO diabetes country profiles 2016. https://www.who.int/diabetes/ country-profiles/diabetes_profiles_explanatory_notes.pdf?ua 1 (accessed 31 March 2020).

23. World Health Organization. Noncommunicable diseases country profiles 2018. https://www.who.int/ nmh/publications/ncd-profiles-2018/en/ (accessed 31 March 2020).
.

$\mathrm{nmh} /$ publications/ncd-profiles-2018/en/ (accessed 31 March 2020).
24. Hofman KJ, Tollman SM. Population health in South Africa: A view from the salt mines. Lancet Glob Hofman KJ, Tollman SM. Population health in South Africa: A view from
Health 2013;1(2):e66-e67. https://doi.org/10.1016/s2214-109x(13)70019-6

25. Gomez-Olive FX, Rohr JK, Roden LC, Rae DE, von Schantz M. Associations between sleep parameters, non-communicable diseases, HIV status and medications in older, rural South Africans. Sci Rep 2018;8:17321. https://doi.org/10.1038/s41598-018-35584-0

26. Vaughn MG, Salas-Wright CP, Maynard BR. Dropping out of school and chronic disease in the United States. J Public Health 2014;22(3):265-270. https://doi.org/10.1007/s10389-014-0615-x

27. De Wet N, Frade S. Disease prevalence and grade repetition among adolescents in South Africa: Is there any relationship? S Afr J Child Health 2018;12(2 Suppl 1):S67-S70. https://doi.org/10.7196/SAJCH.2018. v12i2.1504

28. Statistics South Africa. Morbidity and mortality patterns among the youth of South Africa, 2013. Report No. 03-09-12. Pretoria: Stats SA, 2015. http://www.statssa.gov.za/publications/Report-03-09-12/ Report-03-09-122013.pdf (accessed 31 March 2020).

29. Hinsliff-Smith K, McGarry J, Moreoagare R. What are the experiences of women and girls in South Africa who access healthcare facilities as a result of sexual assault or sexual violence? National Institute for Health Research, 21 January 2019. http.//www.crd.york.ac.uk/PROSPERO/display_record. php?ID=CRD42019121580 (accessed 5 March 2021).

30. Rogan M. Gender and multidimensional poverty in South Africa: Applying the global multidimensional Rogan M. Gender and multidimensional poverty in South Africa: Applying the global multidimensional
poverty index (MPI). Soc Indicat Res 2016;126(3):987-1006. https://doi.org/10.1007/s11205-015-0937-2

poverty index (MPI). Soc Indicat Res 2016;126(3):987-1006. https://doi.org/10.1007/s 11205-015-0937-2
1. Allen L, Williams J, Townsend N, et al. Socioeconomic status and non-communicable disease behavioural . Allen L, Williams , Townsend $\mathrm{N}$, et al. Socioeconomic status and non-communicable disease behavioural
risk factors in low-income and lower-middle-income countries: A systematic review. Lancet Glob Health risk factors in low-income and lower-middle-income countries: A system
2017;5(3):e277-e289. https://doi.org/10.1016/S2214-109X(17)30058-X

32. Burger EH, Groenewald P, Rossouw A, Bradshaw D. Medical certification of death in South Africa moving forward. S Afr Med J 2015;105(1):27-30. https://doi.org/10.7196/SAMJ.8578

Accepted 11 November 2020 